\title{
Análise crítica dos rituais no contexto da enfermagem médico-cirúrgica
}

\author{
CRITICALANALYSIS OF RITUALS IN THE MEDICALAND SURGICAL NURSING SETTING
}

ANÁLISIS CRÍTICO DE LOS RITUALES EN EL CONTEXTO DE LA ENFERMERÍA MÉDICO-QUIRÚRGICA

\author{
Márcia Maria Fontão Zago', Lídia Aparecida Rossi²
}

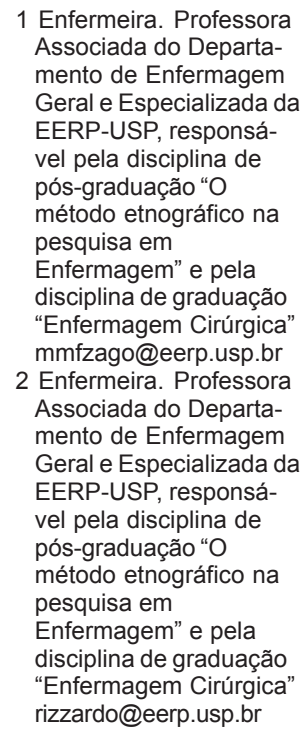

1 Enfermeira. Professora Associada do Departamento de Enfermagem Geral e Especializada da EERP-USP, responsável pela disciplina de pós-graduação "O método etnográfico na pesquisa em

Enfermagem" e pela disciplina de graduação "Enfermagem Cirúrgica" mmfzago@eerp.usp.br

2 Enfermeira. Professora Associada do Departamento de Enfermagem Geral e Especializada da EERP-USP, responsável pela disciplina de pós-graduação "O método etnográfico na pesquisa em Enfermagem" e pela disciplina de graduação "Enfermagem Cirúrgica" rizzardo@eerp.usp.br

\author{
RESUMO \\ Neste artigo, apresentamos \\ uma revisão histórica dos \\ significados dos rituais na \\ enfermagem, com o objetivo \\ de analisar criticamente a \\ prática ritualística da \\ enfermagem cirúrgica. \\ As ações ritualísticas da \\ enfermagem e da enfermagem \\ cirúrgica encontram respaldo \\ na história da profissão, na \\ formação dos enfermeiros e \\ nos mitos do contexto \\ organizacional e cultural \\ cirúrgico. Essas ações são \\ criticadas pelos autores, \\ frente ao pensamento teórico \\ profissional atual.
}

\section{PALAVRAS-CHAVE}

Enfermagem. Enfermagem cirúrgica. Cultura.

Comportamento ritualístico.

\section{SUMMARY}

In this article, a historical review of the meanings of nursing rituals is presented aiming at constructing $a$ critical analysis of the ritualistic practice in surgical nursing. Ritualistic actions in nursing and surgical nursing are supported by the history of the profession, by nurses' education and by the myths in the organizational and cultural and surgical settings. These actions are criticized by authors in face of the present theoretical and professional thought.

\section{KEYWORDS}

Nursing. Surgical nursing. Culture.

Cerimonial behavior.

\section{RESUMEN}

En este artículo presentamos una revisión histórica de los significados de los rituales en la enfermería, con el objetivo de analisar a práctica ritualística de la enfermería quirúrgica. Las acciones ritualísticas de la enfermería y de la enfermería quirúrgica encuentran respaldo en la história de la profesión, en la formación de los enfermeros $y$ en los mitos del contexto organizacional y cultural quirúrgico. Esas acciones son criticadas por los autores, frente al pensamiento teórico profesional actual.

\section{PALABRAS-CLAVE}

Enfermería. Enfermería quirúrgica. Cultura. Conducta ceremonial. 


\section{INTRODUÇÃO}

A Enfermagem Cirúrgica é uma especialidade que tem como objeto o cuidado ao indivíduo submetido a um tratamento cirúrgico. No âmbito do hospital, a Enfermagem Cirúrgica mantém estreitas relações com pacientes, familiares e outros profissionais, como o cirurgião, a nutricionista, a psicóloga, o fisioterapeuta e outros.

Os enfermeiros cirúrgicos constituem um grupo cultural que sofre influências da Enfermagem, do modelo médico-cirúrgico e dos outros grupos profissionais. Porém, os padrões culturais são próprios de cada grupo e inclui-se aqui a interpretação do papel profissional, dos significados da doença, do tratamento e da reabilitação do paciente.

As relações sociais no dia a dia do trabalho dos enfermeiros com diferentes pessoas podem ser conflitantes. Entender essas relações e essa diversidade cultural é um ponto crítico para favorecer a qualidade do trabalho do enfermeiro cirúrgico.

A compreensão desses aspectos culturais pode ser alcançada pela etnografia. Em termos teóricos, a etnografia tem como foco a cultura de um grupo, no seu ambiente natural. A etnografia, como abordagem teóricometodológica, possibilita a geração de conceitos e teorias descritivas, que contribuem para o desenvolvimento do conhecimento básico e específico da enfermagem. Cada estudo etnográfico, por se constituir em uma descrição detalhada da realidade dos participantes em um determinado contexto cultural em período de tempo particular, representa uma parte do conhecimento e da história da enfermagem ${ }^{(1)}$.

Entre os vários conceitos e teorias que abordam a cultura da enfermagem, os que se referem aos rituais da prática são relevantes para a enfermagem como profissão e, especialmente, para a enfermagem cirúrgica.

Esse artigo tem o objetivo de analisar criticamente a prática ritualística da enfermagem cirúrgica. Para tanto, realizamos uma revisão histórica de estudos etnográficos e artigos que tratam do tema e que formam a base teórica para a análise crítica.

\section{A CULTURADA ENFERMAGEM E} O CONCEITO DE RITUAL

Cultura é uma estrutura densa que encontra a sua expressão no conhecimento, nas crenças, nas convicções, na moral e nas normas que regem o comportamento social das pessoas. A cultura caracteriza-se por ser aprendida, compartilhada e relaciona-se com as estruturas invisíveis da sociedade, que são transferidas de uma geração à outra. Cultura implica em um tipo de "tradição social" pela qual as pessoas criam uma história coletiva. Assim, a cultura é uma construção histórica e social ${ }^{(2-3)}$.

O sistema cultural da enfermagem ou a cultura da enfermagem tem características específicas: linguagem, padrão de vestimenta e regras comportamentais. A enfermagem é um fenômeno cultural e como tal é necessário identificar e considerar os pressupostos e os valores que determinam as suas diferentes ações e seus significados. Ao estudarmos o sistema de significados culturais de um grupo, precisamos diferenciar o que as pessoas dizem e o que elas realmente valorizam em suas ações e o que fazem.

Também, não devemos esquecer das origens da profissão, da formação dos profíssionais, dos valores e das dificuldades dos profissionais relacionadas às questões de gênero $\mathrm{e}$ poder, amplamente discutidas na literatura.

O conceito de ritual foi descrito por Turner, no estudo de povos primitivos, como uma cerimônia padronizada, na qual predominam os comportamentos expressivos, simbólicos, místicos, sagrados e irracionais, sobre o comportamento prático, técnico, racional e científico $^{(4)}$.

Os rituais são definidos como um padrão formal e prescrito de comportamento cultural, sem qualquer benefício imediato para o indivíduo. Eles são integrantes de todos os grupos humanos e são usualmente entendidos como um fenômeno social, que oferecem segurança e que beneficiam a comunidade, pois se constituem em ações que transmitem o conhecimento e as práticas tradicionais ${ }^{(4)}$.

No trabalho cotidiano da enfermagem há ações que são repetidas, valorizadas e consideradas como típicas da profissão. Um dos exemplos mais estudados é a passagem de plantão. Como uma ação ritualística, ela ocorre em períodos determinados, com comportamentos
Análise crítica dos rituais no contexto da enfermagem médico-cirúrgica 


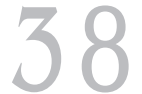

Rev Esc Enferm USP 2003; 37(1): 36-43 específicos e com uma atitude de prontidão do enfermeiro em estar presente - estas são regras culturais. Da mesma forma, o uniforme utilizado pelo enfermeiro é parte de um ritual de vestimenta, em que a roupa branca, tal como a do médico, tem um significado simbólico, pois, cria uma realidade de grupo para esse profissional.

Na enfermagem, o ritual está relacionado com a manutenção da prática guiada pelo modelo de trabalho funcional, determinado pelo cumprimento de tarefas e rotinas. Essa modalidade de trabalho é necessária para manter a ordem da unidade. Portanto, a criação de rotinas e rituais possibilitam a padronização do cuidado de enfermagem, dando um senso de segurança para os enfermeiros ${ }^{(5)}$.

Os rituais também se relacionam com as questões de gênero e poder, mostrando como o mundo é protegido, quem detém o poder e, portanto, devem ser respeitados por seus elementos. A enfermagem, como uma profissão dominada pelo gênero feminino, os seus valores abrangem concepções estereotipadas, mitos e modelos que, inevitavelmente, afetam o modo como a sua cultura se molda. O poder visível e invisível do enfermeiro está intimamente associado com a prática cotidiana da enfermagem. O poder visível pode ser considerado sob as hierarquias entre os diferentes grupos profissionais. O poder invisível está expresso na relação do enfermeiro com o paciente ${ }^{(5-6)}$.

Não podemos deixar de considerar que o hospital é um cenário complexo, que apresenta muitas transformações nas práticas terapêuticas. Ele coloca frente a frente grupos profissionais clássicos e emergentes, e é a instituição que dá sustentação ao modelo médico de assistência, considerado socialmente legítimo. Entretanto, a crescente complexidade dos progressos técnicos de diversas áreas da ciência, que se integram aos avanços da medicina e da cirurgia, confrontam novas e múltiplas especialidades profissionais, que introduzem a interdependência, rompendo com a exclusividade médica da assistência no processo saúde-doença.

Frente a todos esses aspectos que integram a prática ritualística de enfermagem, buscamos entender o ritual, não na sua concepção tradicional como mágico e religioso, mas como pensamento secular, técnico e expresso na atividade científica. Assim, procuramos analisar ritual e ciência no contexto do hospital e da cirurgia.

\section{OS RITUAIS NO CONTEXTO} MÉDICO-CIRÚRGICO

A primeira descrição de ritual na enfermagem foi apresentada por Menzies ${ }^{(7)}$, no início da década de 60. A autora descreveu os rituais da enfermagem em uma instituição hospitalar de ensino inglesa, envolvendo a maioria dos enfermeiros, entre eles os cirúrgicos. Com base na perspectiva psico-analítica e etnográfica, a autora considera que os rituais na enfermagem são importantes e sagrados, pois mantêm a coesão social entre os profissionais. Além disso, o ritual relaciona-se com os mecanismos de defesa contra o estresse do trabalho. A autora identificou como principais conflitos cotidianos do enfermeiro que levam ao estresse: o estereotipo do enfermeiro relacionado ao gênero feminino; a sua apresentação ora como anjo inocente, ora como símbolo sexual; o trabalho não bem remunerado e de baixo status social; o histórico e conflituoso relacionamento entre enfermeiros e médicos (subordinação das ações de enfermagem às ordens médicas, comunicação linear e ascendente entre eles); a necessidade de aprimoramento profissional para acompanhar e atuar com os avanços tecnológicos e terapêuticos; a responsabilidade de coordenar um grupo de profissionais nem sempre preparado, muitas vezes desmotivado e de promover a educação continuada; a responsabilidade pelo gerenciamento da assistência ao paciente, porém, afastado do cuidado; a falta de recursos materiais e humanos para a promoção da assistência com qualidade; e as pressões financeiras e estruturais da organização sob a enfermagem. Para a autora, esses conflitos favorecem o desenvolvimento de normas de comportamento e interferem na capacitação simbólica dos profissionais e dos alunos de graduação em enfermagem, impedindo que eles atuem conscientemente.

O impacto desse estudo na enfermagem foi intenso. A partir de então, surgiram vários artigos que valorizaram a concepção mística do ritual e da sua finalidade de coesão social entre os profissionais.

$\mathrm{Na}$ análise dos estudos realizados, encontramos diferentes exemplos de ações ritualísticas na enfermagem ${ }^{(6,8-14)}$ : a mensuração dos sinais vitais; a anotação de enfermagem; a passagem de plantão; os registros especiais, como o registro de erro na medicação e de queda do paciente; o banho, relacio- 
nado com as regras de higiene; a orientação do paciente, relacionada com a valorização simbólica da educação e outras.

As razões para essas ações e atitudes ritualísticas são apresentadas sob as seguintes justificativas: a formação do enfermeiro focalizada no treinamento e não num processo de educação criativo que favoreça a aprendizagem de estratégias cognitivas para solucionar problemas; no estereotipo de gênero que ainda impede o reconhecimento profissional e que estabelece um contexto masculino nas linhas de poder, dentro da instituição hospitalar; na imaturidade da pesquisa, na falta de consciência para a pesquisa e para a aplicação dos resultados obtidos pela pesquisa no cuidado; nos mecanismos de defesa ao estresse utilizados, levando os enfermeiros a realizar uma série de tarefas desnecessárias e mecanicistas, sem base científica, lidando racionalmente com o problema causador do estresse e depois se concentrando em lidar com as emoções geradas pelo estresse, mas ignorando a sua causa; e a influência de atitudes e crenças, tal como "isso tem que ser feito", que reproduzem conceitos do modelo funcionalista do trabalho, impedindo a implementação de novos conhecimentos $^{(8-14)}$. É importante destacar que todas essas justificativas dos enfermeiros para a prática ritualística são sempre externas ao profissional.

O grande conflito que domina a enfermagem nas duas últimas décadas é: cuidar e gerenciar? ou cuidar ou gerenciar? As dificuldades dos enfermeiros em perceber as suas funções com clareza podem ser devidas a sua formação acadêmica, que introjeta no aluno a preocupação com o cuidado direto como objeto do seu trabalho. Ao se confrontar com o exercício da prática, o profissional é conduzido a executar atividades administrativas burocráticas, distanciando-se do objeto para o qual foi formado, não conseguindo aplicar os conhecimentos adquiridos ${ }^{(10,14)}$.

A realidade clínica determina o contexto socialmente constituído, que afeta o modo de fornecer o cuidado. Este contexto incorpora as crenças, as expectativas, as normas, os comportamentos e as transações comunicativas associadas à doença e ao cuidado à saúde. A realidade clínica também inclui uma realidade simbólica que capacita os indivíduos a darem sentido às suas experiências e ajuda no desenvolvimento de uma identidade pessoal, de acordo com as normas sociais e culturais ${ }^{(2)}$.
Nos contextos de cuidado à saúde, a realidade clínica é mediada por uma realidade simbólica, como a linguagem. A linguagem é um sistema cultural que une os pensamentos e as ações. Os seres humanos impõem restrições e limites para evitar o caos, por meio de ações verbais. Os meios estruturais são usados para organizar o tempo e o espaço em ciclos culturais e regulamentar as esferas de ação pelas rotinas. Essas ações de rotinas formam rituais que fornecem o controle dos aspectos sociais da vida cotidiana ${ }^{(2)}$.

Desse modo, o conceito de ritual não deve ser associado apenas aos domínios do transcendental e do sagrado. Em muitos casos, os rituais estão intricados em complexas relações sociais.

Os ritos refletem claramente os valores estabelecidos nas regras e normas. Um ritual é uma forma especial de comunicação humana, um processo pelo qual a ideologia é criada. A ideologia surge como algo que ninguém pode desafiar e o estabelecimento do ritual assegura que ela permaneça protegida. Para compreender como a ideologia é criada por meio dos rituais, devemos obter uma compreensão dos mecanismos desse processo(2)

Há concordância entre os autores de que os rituais envolvem um elemento geral que substitui a representação social de um mundo para outro. Esta substituição indica como se constituem as transições entre os estados cognitivos e as posições sociais.

No ritual da passagem de plantão, o principal aspecto simbólico está representado pelo "poder delegado do controle médico". Os enfermeiros não se sentem completamente iniciados até que eles conheçam os seus pacientes, ou seja, recebam o plantão e vejam os pacientes. Por esse ritual, os enfermeiros definem seus direitos e obrigações e é esperado que as pessoas comportem-se de acordo com as normas e padrões habituais, devido à posição social que ocupam no sistema hierárquico $^{(8,12)}$.

Por estar com o poder delegado, o enfermeiro tem que comandar a complexa rede de conhecimentos sobre as condições anteriores e atuais de saúde de cada paciente, o que consome considerável tempo e energia. Frente a essa situação, o enfermeiro dá pouca atenção ao cuidado de enfermagem. Desse modo, a passagem de plantão não é usada como meio de comunicar as atividades de enfermagem
Análise crítica dos rituais no contexto da enfermagem médico-cirúrgica 
Márcia Maria Fontão Zago Lídia Aparecida Rossi ou para o desenvolvimento da equipe, mas, para torná-la visível e elevar o seu status de conhecimento no cuidado de enfermagem. $\mathrm{O}$ poder de controle médico delegado tem que ser assumido e realizado, deixando de lado o cuidado de enfermagem que é atualmente considerado o aspecto essencial do trabalho da enfermagem ${ }^{(12)}$.

Os rituais clínicos também podem ser classificados como rituais terapêuticos e ocupacionais. Os rituais terapêuticos são identificados como ações simbólicas que melhoram a condição dos pacientes (ritual do cuidado do corpo pós-morte, ritual da administração dos medicamentos, ritual das práticas assépticas como banho), e rituais ocupacionais (ritual da passagem de plantão) ou rituais de socialização que incluem ações simbólicas que facilitam a transição ou o rito de iniciação dos recém formados, no papel profissional $^{(14)}$.

Os rituais ocupacionais e terapêuticos não são uma exclusividade dos enfermeiros. Skewes ${ }^{(15)}$ critica os rituais médicos no cuidado da integridade da pele e das úlceras de pressão. Segundo a autora, os conhecimentos sobre as feridas e o seu cuidado tiveram grande avanço nas últimas décadas, porém, alguns rituais médicos ainda resistem.

A reunião clínica, amplamente utilizada pelos médicos, no contexto hospitalar, também é um ritual ocupacional. A visão sociológica do diagnóstico e das decisões sobre o tratamento focaliza os modos nos quais as crenças do ser médico são comunicadas entre os médicos, os modos nos quais os colegas aprendem a falar sobre seus problemas e os modos pelos quais eles reforçam suas obrigações com os pacientes, que justificam suas ações. As reuniões clínicas, como rituais ocupacionais, fornecem um contexto para discussão do que está errado com um paciente, do que pode e deveria ser feito ${ }^{(16)}$.

Tanner ${ }^{(9)}$ relata que, no início da década de 70, o desenvolvimento do plano de cuidados foi inserido na educação em enfermagem como um método de ensino e para avaliar o uso do processo de enfermagem pelos alunos. Nessa inserção, estava implícito o pressuposto de que o processo de enfermagem era uma atividade analítica de solução de problemas, fundamental para a tomada de decisão sobre o cuidado. Entretanto, o seu estudo mostrou que nem os estudantes de enfer- magem nem os enfermeiros clínicos utilizam o processo de raciocínio crítico para analisar as situações do paciente. Os enfermeiros derivam seus julgamentos de avaliações qualitativas, na combinação dos sentidos (tato, olfato e visão) e na interpretação das expressões físicas, verbais e comportamentais do paciente. Assim, o processo de enfermagem tende a ser usado de forma ritualística.

O estudo etnográfico realizado por Rossi ${ }^{(17)}$ corrobora essa afirmação. A pesquisadora descreve que o processo de enfermagem, em uma unidade de queimados de um hospital de ensino brasileiro, foi operacionalizado como uma atividade burocrática. A prescrição de enfermagem configurou-se como uma ação ritualística, dissociada da avaliação do paciente. O processo de enfermagem, que deveria ser resultado do pensamento crítico, foi incorporado à prática como mais um ritual, exemplificando a preocupação com a questão da substituição de velhos rituais por novos. Por analogia, preocupa-nos a possibilidade de que a mesma situação possa ocorrer com a utilização das taxionomias de diagnósticos de enfermagem. No Brasil, essa proposta tem sido considerada inovadora e entende-se que poderia assegurar uma prática fundamentada no processo de raciocínio crítico. Entretanto, o mesmo estudo mostra que a fase diagnóstica também pode ser incorporada como um novo ritual, pois muitas vezes é realizada sem conexão com as outras etapas do processo de enfermagem.

No início da década de 90, estudo etnográfico com grupos de enfermeiros descreveu que o comportamento ritualístico prevaleceu entre os enfermeiros de unidade cirúrgica, com a função de criar coesão entre os enfermeiros, sem afetar adversamente os pacientes ${ }^{(18)}$.

O significado social da cirurgia, entre os cirurgiões e os outros elementos da equipe cirúrgica, foi abordado por Fox ${ }^{(19)}$. No estudo, o autor focalizou todos os ambientes sociais da cirurgia (sala de operação, centro cirúrgico, unidade de recuperação anestésica e enfermarias) e descreveu o circuito da higiene e seus rituais, a divisão do trabalho entre cirurgiões e anestesistas e suas autonomias clínicas, o paciente e sua doença, a situação cirúrgica entre os participantes, o discurso sobre a fisiologia do corpo e da ferida cirúrgica, a recuperação e alta do paciente. Assim, o significado social da cirurgia pôde ser compreendido pelas seguintes dimensões: 
- as práticas assépticas da sala de operação servem para dar sustentação à preocupação com a contaminação cirúrgica. Os atos assépticos estão relacionados com a segurança bacteriológica e assumem uma marca retórica de que o processo de ressecção cirúrgica é diferente de outras agressões à integridade do corpo. Para que os cirurgiões tenham uma legitimação do que fazem, essas marcas são importantes para manter o seu status e a sua autoridade;

- as rotinas cirúrgicas são uma forma de obter racionalidade no empreendimento cirúrgico, imposto pela instituição, com a finalidade de aumentar a eficiência no uso dos recursos do hospital;

- o poder social do cirurgião é intensamente buscado nas suas relações com os outros médicos e com a instituição hospitalar; esse poder é obtido por sua capacidade de julgamento, habilidade técnica, profissionalismo e por curar a doença do paciente;

- os elementos da cirurgia a definem como diferente de outras especialidades clínicas, devido ao uso técnicas anestésicas e sua ênfase na esterilização. Essas técnicas são privilegiadas, marcam o significado do que está sendo feito na cirurgia e os meios pelos quais os cirurgiões podem usar estratégias discursivas para sustentar sua autoridade.

Assim, o significado social da cirurgia é fundamentado na retórica sobre a assepsia e a cicatrização. A autoridade e o prestígio do cirurgião derivam das tecnologias, num sentido amplo, desenvolvidas pela medicina moderna. Esse significado também foi observado no estudo de $\mathrm{Katz}^{(20)}$, sobre o ritual na sala de operação.

Certamente a enfermagem cirúrgica compartilha essa visão, que fornece o respaldo para as suas práticas ritualísticas. Em conseqüência dessa visão, o ensino e a prática da enfermagem cirúrgica, até os dias de hoje, dão ênfase aos procedimentos cirúrgicos prescritivos e ritualísticos, como o preparo pré-operatório (banho, tricotomia, orientação do paciente, etc), os procedimentos do trans-operatório (assepsia da pele, posicionamento do paciente na mesa cirúrgica, etc) e do pós-operatório (curativo asséptico, deambulação precoce, movimentação ativa no leito, etc).
Muitos desses procedimentos já foram estudados e demonstraram ser eficazes para favorecer a recuperação fisiológica do paciente, quando aplicados após uma avaliação objetiva das suas condições fisiológicas e identificados como realmente necessários.

Outro ritual descrito na enfermagem cirúrgica refere-se à orientação de pacientes, descrito por $\mathrm{Zago}^{(21)}$. Esse ritual tem funções sociais (mantém a coesão), psicológicas (é função do enfermeiro) e protetoras (protege o paciente do estresse cirúrgico) para o enfermeiro. A orientação do paciente visa o oferecimento de informações orais, os seus conteúdos são padronizados, ocorre em determinados períodos operatórios, o processo não é avaliado e, portanto, o paciente é um agente passivo no processo. O significado desse ritual está fundamentado no modelo de trabalho baseado em rotinas e tarefas, nas suas concepções sobre o cuidado e nas suas limitações para lidar com o estresse do paciente e do trabalho. Nesse sentido, o termo orientação e a ação ritualística são simbólicos para os enfermeiros, pois, mesmo reconhecendo as limitações dessa prática, a força da cultura organizacional não permite que os enfermeiros desenvolvam o ensino do paciente, que é o processo que favorece a participação ativa do paciente, no seu cuidado a saúde.

Assim, os rituais da enfermagem cirúrgica são amplamente justificados pelos profissionais, pois representam a prática incorporada a suas realidades organizacionais e culturais.

\section{PARA ALÉM DO RITUAL}

Em defesa dos rituais na enfermagem,

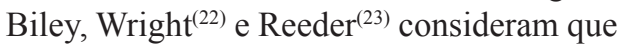
eles são históricos e importantes para manter o papel profissional. Afirmam que, embora eles não sejam baseados em princípios científicos, os rituais englobam conhecimentos do ser humano e os enfermeiros expressam esses conhecimentos pela arte de cuidar.

Entretanto, para Walsh, Ford ${ }^{(10)}$ e Ford, Walsh $^{(14)}$, a ação ritual implica em implementar uma tarefa sem problematizá-la. Martin ${ }^{(13)}$ e De Luca $^{(24)}$ consideram que os rituais distanciam o enfermeiro do paciente, ajudam a manter a estrutura hierárquica do seu poder sobre os outros membros da equipe de enfermagem, enaltece o modelo funcional de assistência e potencializa uma cultura opressiva.
Análise crítica dos rituais no contexto da enfermagem médico-cirúrgica 
Márcia Maria Fontão Zago Lídia Aparecida Rossi
As rotinas e a mitologia envolvida nos rituais têm influenciado os aspectos da vida e do cuidado à saúde, através da história das diferentes culturas. Consideramos que os rituais são importantes como parte do modo como todo grupo social celebra, mantém e renova o mundo no qual vivem.

Os rituais ilustram a unidade dos enfermeiros como grupo social. Os rituais de enfermagem vão além do servir como apoio ao status quo, pois, eles combinam a prática e $\mathrm{o}$ simbólico, em situações específicas. Por isso, eles devem ser vistos com interesse e não serem expurgados simplesmente por serem considerados negligentes ou obsessivos.

Em relação ao ritual terapêutico, compreendemos que ele não lesa o paciente, mas, certamente, em nada contribui para um cuidado que lhe produza bem estar ou que seja de melhor qualidade.

Na mesma linha de raciocínio, consideramos que o ritual ocupacional também não lesa o paciente e promove a coesão dos enfermeiros. Porém, é importante considerarmos o sentido do termo coesão. Esse conceito é originário do positivismo sociológico, que preconiza que a sociedade tem mecanismos para controlar as influências externas ou internas que podem ameaçar o seu equilíbrio. O sistema social tem a tendência (visão teleológica) à conservação e à reprodução; por isso, as inovações, as invenções e tensões revitalizam o sistema social. Assim, as mudanças sociais não atingem as estruturas, não são revolucionárias e, portanto, mantêm o status quo dos indivíduos. Para o positivismo social, as leis que regem os fenômenos sociais são atemporais, invariáveis e tendentes à estabilidade e à coesão ${ }^{(25)}$. Com essa visão, Walsh e Ford ${ }^{(10)}$ consideram que há um entendimento entre os enfermeiros de que os rituais dão um sentido de continuidade, favorecendo que as regras e os procedimentos sejam seguidos em qualquer contexto de cuidado à saúde ${ }^{(10)}$.

Por outro lado, o conceito de resistência à dominação, derivado do interacionismo simbólico ${ }^{(26)}$, possibilita a compreensão do ritual ocupacional como um processo de resistência à mudança. Como tal, ele coloca limites para o pensamento, o diálogo reflexivo e a crítica.

Alterar a prática ritualística da enfermagem e da enfermagem cirúrgica implica mudar a cultura dos enfermeiros. Cultura é primaria- mente influenciada pelo ambiente interno e externo de um grupo ou organização. A cultura também tem componentes influenciadores e de resultados, ou seja, o resultado de certas atitudes e crenças da enfermagem leva a determinadas ações. Essas características fazem com que os enfermeiros sejam resistentes a mudanças ${ }^{(10,14)}$.

As estratégias para a mudança cultural da enfermagem são ${ }^{(14,24)}$ : maximizar a participação da equipe nas decisões do cuidado, evitar decisões ascendentes e de coerção, evitar a burocracia, refletir criticamente sobre a prática, promover a educação como meio para a práxis e exercer liderança sensível aos avanços do conhecimento.

Como enfermeiras, pesquisadoras e docentes de enfermagem cirúrgica, reconhecemos que a situação cirúrgica é estressante para o paciente, sua família e todos os profissionais envolvidos no processo. Portanto, concordamos com os autores citados de que é essencial que os enfermeiros desenvolvam mecanismos de enfrentamento mais efetivos para lidar com o estresse e com suas dificuldades.

A enfermagem contemporânea tem tentado alterar as ideologias e as crenças apresentadas, por meio de pesquisas, transferindo as suas prioridades para a melhoria do cuidado ao paciente. A luta pelo reconhecimento profissional envolve desenvolver conhecimentos que levem a novos pressupostos, conceitos e técnicas, que sejam identificados como inerentes à enfermagem.

As reflexões apresentadas levam-nos a considerar que o ensino de enfermagem cirúrgica deve ser desenvolvido sem conotação prescritiva e ritualística, tendo como base os pressupostos do cuidado humanizado e os procedimentos cientificamente validados, por meio de estratégias específicas da enfermagem, como o processo de enfermagem e a taxionomia dos diagnósticos de enfermagem. É dessa forma que poderemos desenvolver a práxis nos alunos e futuros profissionais.

Se quisermos fundamentar nossas ações no conhecimento científico, a prática dos rituais em nada irá contribuir para a emancipação da Enfermagem como ciência e, muito menos, será o meio pelo qual devemos buscar a nossa emancipação profissional e social. 
(1) Morse JM, Field PA. Qualitative research methods for health professionals. Thousands Oaks: Sage; 1995.

(2) Kleinman A. The illness narratives: suffering, healing and the human condition. Los Angeles: Basic Books; 1988.

(3) Helman CG. Cultura, saúde e doença. $2^{\mathrm{a}}$ ed. Porto Alegre: Artes Médicas; 1994.

(4) Turner VW. O processo ritual: estrutura e antiestrutura. Petrópolis: Vozes; 1974.

(5) Van Maanen JMT. Janforum: the nursing profession: ritualized, routinized or researchbased? J Adv Nurs 1979; 4: 87-98.

(6) Suominen T, Kovasin M, Ketola O. Nursing culture: some viewpoints. J Adv Nurs 1997; 25:186-90.

(7) Menzies IEP. A case-study in the functioning of social systems as a defence against anxiety. Human Relations 1960; 13: 95-121.

(8) Walker VH. Nursing and ritualistic practice. New York: Macmillan; 1967.

(9) Tanner CA. The nursing care plan as teaching method: reason or ritual? Nurse Educ 1986; 11:8-10.

(10) Walsh M, Ford P. Nursing rituals: research and rational actions. 9th ed. Oxford: Butterworth-Heineman; 1990.

(11) Wolf ZR. The bath: a nursing ritual. J Adv Nurs 1993; 27: 135-48.

(12) Ekman I, Segesten K. Deputed power of medical control: the hidden message in the ritual of oral shift reports. J Adv Nurs 1995; 22: 1006-11.

(13) Martin GW. Ritual action and its effect on the role of nurse as advocate. J Adv Nurs 1998; 27: 189-94.

(14) Ford P, Walsh M. New rituals for old: nursing throught the looking glass. $2^{\text {nd }}$ ed. Oxford: Butterwork - Heinemann; 1995.
(15) Skewes SM. Skin care rituals that do more harm than good. AJN 1996; 96: 33-5.

(16) Bosk CL. Occupacional rituals in patient management. N Engl J Med 1980; 303:71-6.

(17) Rossi LA. O processo de enfermagem em uma unidade de queimados: da ideologia da rotina à utopia do cuidado individualizado. [tese] Ribeirão Preto (SP): Escola de Enfermagem de Ribeirão Preto/USP; 1997.

(18) Holland CK. An ethnographic study of nursing culture as an exploration for determining the existence of a system of ritual. J Adv Nurs 1993; 18: 1461-70.

(19) Fox NJ. The social meaning of surgery. Buckingham: Open University Press; 1992.

(20) Katz P. Ritual in the operating room. Ethnology 1981; 20: 335-50.

(21) Zago MMF. O ritual de orientação dos pacientes entre os enfermeiros cirúrgicos: um estudo etnográfico. [tese] Ribeirão Preto (SP): Escola de Enfermagem de Ribeirão Preto/ USP; 1994.

(22) Biley FC, Wright GS. Towards a defence of nursing routine and ritual. J Clin Nurs 1997; 6: 115-19.

(23) Reeder F. Rituals of healing: ever ancient, ever new. In: Gaut DA, Boykin A, editors. Caring as healing: renewal through hope. New York: National League for Nursing; 1994.

(24) De Luca EK. Reconsidering rituals: a vehicle for education as change. J Contin Educ Nurs 1995; 26: 139-44.

(25) Minayo MCS. O desafio do conhecimento: pesquisa qualitativa em saúde. $2^{\text {a }}$ ed. São Paulo: Hucitec-Abrasco; 1993.

(26) Lock M, Scheper-Hughes N. A criticalinterpretative approach in medical anthropology: rituals and routines of discipline and dissent. In: Johnson TM, Sargent, editors. Medical anthropology: contemporary theory and method. New York: Praeger; 1990. p.47-72.
Análise crítica dos rituais no contexto da enfermagem médico-cirúrgica 